Annals of International Medical and Dental Research

E-ISSN: 2395-2822 | P-ISSN: 2395-2814

Vol-8, Issue-2 | March-April 2022

DOI: 10.53339/aimdr.2022.8.2.14

Page no- 99-108 | Section- Research Article (Medicine)

\title{
Study of Relationship between HbA1c and Microalbuminuria of Diabetic Patients
}

\section{Suman Kanti Chowdhury ${ }^{*}$, Shibani Datta ${ }^{2}$, Muhammad Tanvir Mohith ${ }^{3}$, Soumitra Roy ${ }^{4}$, Md. Jalal Hossain5, Nahida Zafrin6, Mahmudur Rahman7, Abdullah Md Abu Ayub Ansary ${ }^{8}$}

${ }^{1}$ Assistant Professor, Department of Medicine, Sylhet M A G Osmani Medical College, Sylhet, Bangladesh.

Email ID: sumandmck55@gmail.com,

Orcid ID: 0000-0003-0906-2120.

${ }^{2 M D}$ Thesis Part Student, Department of Paediatrics, Sylhet M A G Osmani Medical College, Sylhet,Bangladesh.

Email ID: sdaky13@gmail.com

Orcid ID: 0000-0002-9713-8967.

${ }^{3}$ Assistant Professor, Department of Medicine, Sylhet M A G Osmani Medical College, Sylhet, Bangladesh.

Email ID: drmohithtanvir@gmail.com

Orcid ID: 0000-0002-8458-2308.

4Assistant Professor, Department of Medicine, Sylhet M A G Osmani Medical College, Sylhet, Bangladesh.

Email ID: dr.soumitra68@gmail.com

Orcid ID: 0000-0003-2186-9445.

${ }^{5}$ Assistant Professor, Department of Medicine, Sylhet M A G Osmani Medical College, Sylhet, Bangladesh. Email ID: Jalalh1709@gmail.com, Orcid ID: 0000-0002-9289-7606.

${ }^{6}$ Assistant Professor, Department of Medicine, Sylhet M A G Osmani Medical College, Sylhet, Bangladesh. Email ID: zafrin76@gmail.com,

Orcid ID: 0000-0001-7200-8616.

${ }^{7}$ Medical Officer, 250 Bed District Sadar Hospital, Sunamganj,Bangladesh,

Email ID: mahmudurrocky6747@gmail.com ,

Orcid ID: 0000-0001-5082-3214.

8Junior Consultant (Surgery), OSD, DGHS,

Dhaka, Bangladesh.

Email ID: ansary.mmc@gmail.com,

Orcid ID: 0000-0003-0011-302

${ }^{*}$ Corresponding author

Received: 14 December 2021

Revised: 27 January 2022

Accepted: 08 February 2022

Published: 18 February 2022

\section{Abstract}

Background: Globally, as of 2010, an estimated 285 million people had diabetes, with type 2 making up about $90 \%$ of the cases. Its incidence is estimated to almost double, by 2030. Diabetic nephropathy is a consequence of long standing diabetes. The prevalence of microalbuminuria predicts progression to diabetic nephropathy. Measurement of glycated hemoglobin (HbA1c) has become the preferred method of diagnosis as well as assessing long-term glycaemic control. The present study was conducted to determine the magnitude and prevalence of microalbuminuria in relation to $\mathrm{HbA1c}$ in a group of diabetic patients admitted in Comilla Medical College Hospital of Bangladesh. Objectives: The relationship between $\mathrm{HbA1c}$ and microalbuminuria of diabetic patients was assessed in a hospitalbased cross-sectional study in a tertiary level hospital. Material \& Methods: A hospital-based cross-sectional descriptive study was carried out in department of Medicine, Comilla Medical College Hospital from 1st July, 2011 to 30th June, 2012. One hundred known admitted diabetic patients with age 25-84 years were included in this study. Results: Microalbuminuria had a significant correlation with HbA1c $(p<0.05)(r=0.24)$. Increasing HbA1c was associated with increasing microalbuminuria above optimal cut-off points of HbA1c $7 \%$. The prevalence of microalbuminuria was $33.33 \%$ at HbA1c (6.1$6.9) \%$, whereas it was $75 \%$ at HbA1c $(7.1-7.9) \%$. Microalbuminuria was $38.74 \pm 9.76 \mathrm{mg} / \mathrm{gm}(\mathrm{p}<0.05)$ at $\mathrm{HbA} 1 \mathrm{c}<7 \%$, whereas it was $65.86 \pm$ $21.29 \mathrm{mg} / \mathrm{gm}(\mathrm{p}<0.05)$ at $\mathrm{HbA1c} \geq 7 \%$. Conclusions: The present study found an early onset of microalbuminuria in the selected community which could be due to poor glycaemic control (high $\mathrm{HbA1c} \geq 7 \%$ ) after excluding other causes of microalbuminuria. Screening for microalbuminuria and $\mathrm{HbA1c}$ test should be done in both newly and already diagnosed diabetic patients as an early marker of renal dysfunction and glycaemic control.

Keywords:- HbA1c \& Microalbuminuria, ACR , Diabetes mellitus, Diabetic nephropathy. 
Annals of International Medical and Dental Research

E-ISSN: 2395-2822 | P-ISSN: 2395-2814

Vol-8, Issue-2 | March-April 2022

DOI: 10.53339/aimdr.2022.8.2.14

Page no- 99-108 | Section- Research Article (Medicine)

\section{INTRODUCTION}

Diabetes mellitus (DM) has long been recognized as a major public health problem for its adverse health impact on individuals and for its economic burden on the health care system and the society at large.[1] The International Diabetes Federation (IDF) in 2005 confirmed that diabetes is one of the most common noncommunicable diseases globally and constitutes a major cause of death in most developed countries as well as many devel- oping and newly industrialized countries. [2] The number of adults with diabetes in the world will rise from 135 million in 1995 to 300 million in the year 2025. [3] Patients with Type 2 diabetes often have a long asymptomatic period of hyperglycemia and many have complications at the time of diagnosis. ${ }^{[4]}$ Diabetic Nephropathy is a common conse- quence of longstanding diabetes mellitus. It is characterized by the presence of large amounts of urinary proteins, mostly albumin. [5] Like other microvascular complications, the patho- genesis of diabetic nephropathy is related to chronic hyperglycaemia.[5] The laboratory test for early detection of diabetic nephropathy is the measurement of microalbumin in urine (microalbuminuria). ${ }^{6]}$ There are many conditions causing microalbuminuria but hypertension and diabetes are the two biggest risk factors, besides old age and weight gain. [7] Microalbuminuria predicts progression to diabetic nephropathy and cardiovascular diseases. [8] Increased level of microalbuminuria is associated with increased risk of progressive kidney disease leading towards ESRD and cardiovascular morbidity and mortality in diabetic patients as reported in an earlier study.[9] It is therefore most reliable as an indicator of incipient diabetic nephropathy within the first 10 years of type 1 diabetes, when majority of the patients with microalbuminuria will progress to overt nephropathy within further 10 years. $[10]$ It is also a potentially useful marker of an increased risk of macrovascular disease. [10] According to the American Diabetes Association (ADA), microalbuminuria, defined as urinary albumin excretion rate of $20-200$ $\mathrm{mcg} / \mathrm{min}$ on a timed specimen or 30 - 300 $\mathrm{mg} / \mathrm{gm}$ in urinary ACR (albumin to creatinine ratio) from a spot collection (preferred method) without an alternative clinical explanation (such as urinary tract infection, heart failure or exercise in the past 48 hours) or urinary protein excretion rate of $30-300 \mathrm{mg} /$ day in a $24 \mathrm{hr}$ collection. [5,11,12] 24 hour collection of urine for quantitative assessment of urinary albumin excretion rate is currently considered the gold standard measurement of microalbuminuria.[13] While many experts now support the use of random or first morning tests for urinary albumin to creatinine ratio as a convenient and accurate approach to screening patients. [14] It must be measured on at least two of three measurements over a 2 to 3 month period. [15] A repeat test should be done 3 to 6 months after the first positive test for microalbuminuria.16] Lastly, the test is inaccurate in a person with too much or too little muscle mass. This is due to the variation in creatinine level which is produced by the muscle.117] Some Individual level of microalbumin: a) $24 \mathrm{~h}$ urine collection: $30-300$ $\mathrm{mg} / 24 \mathrm{~h},[18]$ b) Short-time urine collection: 20 $200 \mu \mathrm{g} / \mathrm{min},{ }^{[18]}$ c) Spot urine albumin sample: 30 - $300 \mathrm{mg} / 1$ of urine or $\mu \mathrm{g} / \mathrm{gm}$ of urine,[19] d) Spot urine albumin/creatinine ratio: i) Women: 3.5 - 25 or $35 \mathrm{mg} / \mathrm{mmol}$ or $30-400 \mathrm{mg} / \mathrm{gm}$,[19] ii) Men: 2.5 or $3.5-25$ or $35 \mathrm{mg} / \mathrm{mmol}$ or $30-300$ 
Annals of International Medical and Dental Research

E-ISSN: 2395-2822 | P-ISSN: 2395-2814

Vol-8, Issue-2 | March-April 2022

DOI: 10.53339/aimdr.2022.8.2.14

Page no- 99-108 | Section- Research Article (Medicine)

mg/gm.[19] Current recommendations of the American Diabetes Association (ADA) are to screen for micro- albuminuria once a child is 10 years old and has Type 1 diabetes for 5 years and to screen children with Type 2 diabetes at diagnosis and annually thereafter. [20] $\mathrm{HbA} 1 \mathrm{c}$ is a measure of erythrocyte hemoglobin glycation, since erythrocytes have about 120 days life span, HbA1c reflects mean glycaemic value for the previous 3 months (weighted to the most recent months).[21] Blood samples for $\mathrm{HbA1c}$ can be drawn whether or not the patient is fasting, as it does not reflect the patterns of glycaemia, the effects of food or exercise. $[22,23]$ Increased blood pressure, poor glycaemic control and smoking are some risk factors for micoralbuminuria.110] Glycated hemoglobin (HbA1c) has proved to be a good indicator of long term glycaemic control and reflect the mean glucose value (MGV). A linear relationship with $\mathrm{HbA1c}$, microalbuminuria and the incidence of diabetic nephropathy is known to exist.[24] Significant predictors of microalbuminuria included $\mathrm{HbA1c}$, creatinine, and the presence of hypertension.[25] The present study was carried out in Comilla Medical College Hospital to assess the prevalence of microalbuminuria with relation to $\mathrm{HbA1c}$. Microalbuminuria and $\mathrm{HbA} 1 \mathrm{c}$ were measured as a marker of renal damage and glycaemic control respectively.

\section{MATERIAL AND METHODS}

This cross-sectional descriptive study was carried out in Comilla Medical College Hospital from 1st July, 2011 to 30th june, 2012. One hundred known diabetic patients (58 males and 42 females) with age range 25-84 years were included in this study. Patient complaints of symptoms suggesting diabetes with $\mathrm{FBS} \geq 7$ $\mathrm{mmol} / \mathrm{L}$ or $\mathrm{RBS} \geq 11.1 \mathrm{mmol} / \mathrm{L}$ or $\mathrm{HbA1c} \geq$ $6.5 \%$ \& also known diabetic patients were included in this study. Prior to initiation of this study, the research protocol was approved by Bangladesh College of Physicians and Surgeons (BCPS). The aims and objectives of study were explained to the patients in easily understandable local language and then informed consent was taken from each case. It was assured that all were informed and records were kept confidential and the procedure will be helpful for both the physician and the patients in making rational approach of the case management. Data were collected by semi structured questionnaire by the investigator as soon as possible after the admission of the patient \& were by face to face interview. Information was collected by taking medical history and clinical examination and subsequent laboratory investigations. Proper permission was taken from the concerned departments. Their informed written consent was taken in a consent form before collecting data. Fasting \& two hours after breakfast venous blood and morning urine samples were collected for analysis of FBS, two hours postprandial glucose, creatinine, $\mathrm{HbA1c}$ and microalbuminuria. Those diabetic patients who are hypertensive \& who had other causes of microalbuminuria like recent ( $24 \mathrm{hrs}$ ) vigorous exercise, fever, heart failure, urinary tract infection, prostatitis, menstruation etc. have not been included in the study. Purposive nonprobability sampling technique was used for data collection. A structured questionnaire regarding the demographic data such as age, sex, duration of diabetes, height and body weight were measured. Blood pressure, smoking habit, family history of diabetes, renal disease and hypertension were recorded for 
Annals of International Medical and Dental Research E-ISSN: 2395-2822 | P-ISSN: 2395-2814

Vol-8, Issue-2 | March-April 2022

DOI: 10.53339/aimdr.2022.8.2.14

Page no- 99-108 | Section- Research Article (Medicine)

each patient. The body mass index (BMI) was calculated as weight $(\mathrm{Kg})$ divided by height $(\mathrm{m})$ squared.[26] Venous blood was collected into two test tubes; with no anticoagulant for serum creatinine, and with Ethylene Diamine Tetra Acetic Acid (EDTA) for HbA1c. Morning urine sample was collected in a container (without preservative) for analysis of creatinine and microalbumin. HbA1c was estimated by Boronate affinity chromatography (HPLC) which separates total glycated hemoglobin by binding to solid-phase dihydroxyborate13 using Nycocard Immunoassay kit (USA). Serum creatinine was analysed by alkaline picrate, Jaffe's Method (Biocon Kit). Microalbumin was estimated by Sandwich Format Immunometric Assay method. After collection, all data were checked for inadequacy, irrelevancy and inconsistency. All data were recorded systemically in preformed data collection form and quantitative data were expressed as mean and standard deviation and qualitative data as frequency distribution and percentage. All statistical analysis was done by using SPSS version 13.0. Pearson's correlation co-efficient test was applied to observe association of microalbuminuria with $\mathrm{HbA1c}$. All p values $<0.05$ considered as statistically significant ( $95 \%$ confidence limit).

\section{RESULTS}

Among 100 known case of diabetes mellitus, 29 patients had $\mathrm{HbA1c}<7 \%$, other 71 patients had $\mathrm{HbA} 1 \mathrm{c} \geq 7 \%$. Among 100 known case of diabetes mellitus, 47 patients had microalbuminuria. The prevalence of microalbuminuria was $33.33 \%$ with $\mathrm{HbA1c} 6.1-6.9 \%$, whereas it was $75 \%$ with HbA1c 7.0-7.9 \% \& $52.54 \%$ with $\mathrm{HbA} 1 \mathrm{c} \geq 8.0 \%$. The microalbuminuria of those participants with $\mathrm{HbA} 1 \mathrm{c}$ level $<7 \%$, was $38.74 \pm 9.76$ (mg/gm) (mean \pm $\mathrm{SD})$. On the other hand, it was $65.87 \pm 21.29$ (mg/gm) with HbA1c $\geq 7 \%$. (p<0.05) Microalbuminuria in diabetic patients has shown a significant correlation with HbA1c. $(r=0.24)$ $(p<0.05)$ Pearson's correlation co-efficient test was applied to observe association of microalbuminuria with $\mathrm{HbA1c}$.

Table 1: Distribution of the study participants' age by HbA1c cut-off points.

\begin{tabular}{|l|l|l|}
\hline Age (years) & HbA1c <7\% (n=29) & HbA1c $\geq 7 \%(\mathbf{n = 7 1})$ \\
\hline $25-34$ & $1(3.4)$ & $3(4.2)$ \\
\hline $35-44$ & $5(17.2)$ & $17(23.9)$ \\
\hline $45-54$ & $5(17.2)$ & $22(30.9)$ \\
\hline $55-64$ & $10(34.5)$ & $16(22.54)$ \\
\hline $65-74$ & $4(13.8)$ & $10(14.1)$ \\
\hline $75-84$ & $4(13.8)$ & $3(4.2)$ \\
\hline
\end{tabular}

Table 2: Distribution of microalbuminuria with the study participants' age.

\begin{tabular}{|l|l|l|}
\hline Age ( years) & Risk group $(\mathbf{n = 1 0 0})$ & Prevalence of microalbuminuria(\%) $\mathbf{n = 4 7}$ \\
\hline $25-34$ & 4 & $2(50)$ \\
\hline $35-44$ & 22 & $11(50)$ \\
\hline $45-54$ & 27 & $10(37.03)$ \\
\hline
\end{tabular}


Annals of International Medical and Dental Research E-ISSN: 2395-2822 | P-ISSN: 2395-2814

Vol-8, Issue-2 | March-April 2022

DOI: 10.53339/aimdr.2022.8.2.14

Page no- 99-108 | Section- Research Article (Medicine)

\begin{tabular}{|l|l|l|}
\hline $55-64$ & 26 & $13(50)$ \\
\hline $65-74$ & 14 & $7(50)$ \\
\hline $75-84$ & 7 & $4(57.14)$ \\
\hline
\end{tabular}

Table 3: Association between HbA1c and prevalence of microalbuminuria.

\begin{tabular}{|l|l|l|}
\hline HbA1c $(\%)$ & Risk group $(\mathbf{n = 1 0 0})$ & Prevalence of Microalbuminuria $(\boldsymbol{\%})(\mathbf{n}=\mathbf{4 7})$ \\
\hline$\leq 6.0$ & 8 & $0(0)$ \\
\hline $6.1-6.9$ & 21 & $7(33.33)$ \\
\hline $7.0-7.9$ & 12 & $9(75)$ \\
\hline$\geq 8.0$ & 59 & $31(52.54)$ \\
\hline
\end{tabular}

Table 4: Microalbuminuria of study participants by HbA1c cut-off points.

\begin{tabular}{|l|l|l|}
\hline HbA1c(\%) & Microalbuminuria $(\mathbf{m g} / \mathbf{g m})$ & p value* \\
\hline$<7(\mathrm{n}=29)$ & $38.74 \pm 9.76$ & $<0.05^{*}$ \\
\hline$\geq 7(\mathrm{n}=71)$ & $65.87 \pm 21.29$ & $<0.05^{*}$ \\
\hline
\end{tabular}

Table 5: Correlation of microalbuminuria with HbA1c $(n=100)$.

\begin{tabular}{|l|l|l|l|}
\hline \multirow{2}{*}{$\begin{array}{l}\text { Microalbuminuria } \\
\text { gg/gm (57.99 } \pm 18.01)\end{array}$} & Pearson Correlation, $\mathrm{r}$ & 1 & 0.24 \\
\cline { 2 - 4 } & $\mathrm{p}$ - value & & $<0.05^{*}$ \\
\cline { 2 - 4 } & $\mathrm{n}$ & 100 & 100 \\
\hline \multirow{2}{*}{$\begin{array}{l}\text { HbA1c (\%) } \\
(8.68 \pm 2.26)\end{array}$} & Pearson Correlation, $\mathrm{r}$ & 0.24 & 1 \\
\cline { 2 - 4 } & Sig. (2-tailed) & 0 & 100 \\
\cline { 2 - 4 } & $\mathrm{n}$ & 100 & 100 \\
\hline
\end{tabular}

*highly significant

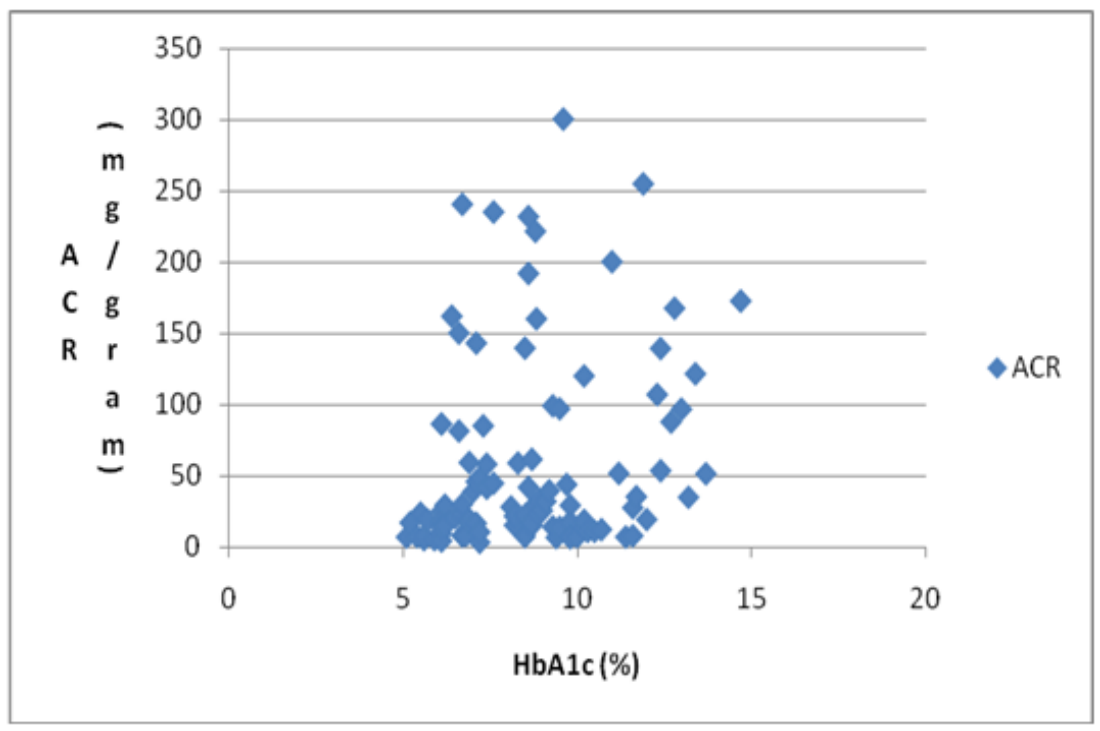

Figure 1: Relationship between $\mathrm{HbA1c} \&$ microalbuminuria 
Annals of International Medical and Dental Research

E-ISSN: 2395-2822 | P-ISSN: 2395-2814

Vol-8, Issue-2 | March-April 2022

DOI: 10.53339/aimdr.2022.8.2.14

Page no- 99-108 | Section- Research Article (Medicine)

\section{DISCUSSION}

From the hundred known diabetic patients studied, 58\% were males and $42 \%$ were females with $64 \%$ having a family history of diabetes. Only $47 \%$ patients have micro- albuminuria, $25 \%$ were male \& $22 \%$ were female. Fasting \& two hours after breakfast plasma glucose of those participants with $\mathrm{HbA1c}<7$ were $7.13 \pm$ $1.1 \mathrm{mmol} / 1$ \& $8.37 \pm 1.9 \mathrm{mmol} / 1$ respectively $(p<0.001)$. Those whom had HbA1c $\geq 7$, their FBS \& two hours after breakfast plasma glucose were $11.1 \pm 3.1 \mathrm{mmol} / 1 \& 14.48 \pm 5.8 \mathrm{mmol} / 1$ respectively $(\mathrm{p}<0.001)$. Serum creatinine of those with $\mathrm{HbA} 1 \mathrm{c}<7$ were $0.96 \pm 0.14 \mathrm{mg} / \mathrm{dl}$ $(p<0.005)$, whereas it was $1.15 \pm 0.41 \mathrm{mg} / \mathrm{dl}$ with HbA1c $\geq 7 \% \quad(p<0.005)$. Microalbuminuria of those patients with $\mathrm{HbA1c}<7$ were $38.74 \pm 9.76$ $\mathrm{mg} / \mathrm{gm}(\mathrm{p}<0.05)$, whereas it was $65.87 \pm 21.29$ $\mathrm{mg} / \mathrm{gm}$ with HbA1c $\geq 7 \quad(\mathrm{p}<0.05)$. Microalbuminuria in diabetic patients has shown a significant correlation with HbA1c $(\mathrm{p}<0.05)$ $(r=0.24)$ [Table 5]. Here, Pearson's correlation co-efficient, $\mathrm{r}$ was 0.24 , which is statistically significant. $[25,26,27,28]$ The prevalence of microalbuminuria was $0 \%$ with $\mathrm{HbA} 1 \mathrm{c}<6 \%$, whereas, it were $33.33 \%$ with HbA1c 6.1 - $6.9 \%$, $75 \%$ with HbA1c 7.0 - 7.9\%, 52.54\% with HbA1c $\geq 8 \%$. The present study was conducted on a group of 100 admitted diabetic patients in Comilla Medical College Hospital. 64\% had family history of diabetes showing that Type 2 diabetes has a strong genetic component and parental history of diabetes is significantly associated with micro- albuminuria. [29,30,31,32] Blood glucose is a continuous variable, rising and falling about 10-folds in people with diabetes. ${ }^{[33]}$ Earlier studies have reported glycosylated hemoglobin to be used as a diagnostic test for Type 2 Diabetes instead of relying only on fasting blood glucose.[33] In the present study as shown in [Table 5] microalbuminuria has a significant correlation with HbA1c $(\mathrm{p}<0.05) \quad(\mathrm{r}=0.24)$, similar to the study reported by Kassab.[9] The complications of both Type 1 and 2 Diabetes do not develop or progress for 6-9 years when the average $\mathrm{HbA1c}$ level is kept at $<7 \%$. [34] The present study found an increase in $\mathrm{HbA} 1 \mathrm{c}$ levels as indicated by a mean value of $8.68 \pm 2.26 \%$. The population in the present study had an early onset of microalbuminuria, similar to that reported in an earlier study. [35] Microalbuminuria is related to hyperglycemia and control of blood glucose level has been shown to prevent the development of nephropathy in Type 1 \& 2 diabetes. [36] The measurement of serum creatinine concentration is widely used clinically as an index of renal function. [30] Serum creatinine concentration is widely affected by age, sex and body weight. [30] Microalbuminuria and serum creatinine increase significantly in Type 2 diabetes as reported in an earlier study.[30] Serum creatinine measurement is a convenient and inexpensive method of assessing renal function and a consistently elevated level indicates chronic kidney disease, but however some patients have a substantial decrease in glomerular filtration rate, while their serum creatinine concentration remains within the normal range and thus it is a poor screening test for mild kidney disease.[37] A rapid decline in renal function can be predicted for patients having poor glycaemic control and micro- albuminuria. ${ }^{[38,39]}$ In adults, a diagnosis of microalbuminuria can precede Type 2 diabetes and is a component of the World Health Organization's definition of the metabolic syndrome.[8] Minimizing microalbuminuria and having a tight glycaemic 
Annals of International Medical and Dental Research

E-ISSN: 2395-2822 | P-ISSN: 2395-2814

Vol-8, Issue-2 | March-April 2022

DOI: 10.53339/aimdr.2022.8.2.14

Page no- 99-108 | Section- Research Article (Medicine)

control is an important treatment goal for patients with diabetes. ${ }^{[40]} \mathrm{HbA1c}$ is an index of mean blood glucose in fasting and postprandial state and is well established and widely used as a clinical measure of chronic glycaemia.4142] Several studies indicate that HbA1c may show a glycaemic threshold with microvascular complications, suggesting it may additionally be useful as a diagnostic test for diabetes. [43,44] In this hospital-based study of over 100 different aged individuals, we found a linear continuous relationship of $\mathrm{HbA1c}$ with microalbuminuria. We found no evidence for a threshold effect of HbA1c with microalbuminuria. It should be noted that the meta-analysis research group on the diagnosis of Diabetes using Glycated Hemoglobin levels has recommended an $\mathrm{HbA1c}$ cut-off point of $\geq 7.0 \%, 4 \underline{45}$ ] which agrees well with our findings. The main strengths of our study are our precise estimation of microvascular endpoints collected using standardized protocols. In addition, $\mathrm{HbA1c}$ was measured according to internationally accepted standards. This is despite the many advantages to using $\mathrm{HbA} 1 \mathrm{c}$ over other glycaemic measures such as less intra-individual variation, $\left.{ }^{44}\right]$ good ability to detect undiagnosed diabetes, $[\underline{46,47]}$ and predict risk of developing microvascular complications both in type 1 and type 2 diabetes, $[48,49,50]$ and widespread acceptance as a common endpoint in clinical trials. However, high $\mathrm{HbA1c}$ levels were still positively associated with microvascular complications (e.g. those with an $\mathrm{HbA1c}$ level above $8 \%$ were fifty two times as likely to have microalbuminuria than those with an $\mathrm{HbA1c}$ below 6\%). Despite the lack of an abrupt threshold, together with the significant advantages of HbA1c over other glycaemic measures, for example, no requirement of fasting, less variability, consistent associations with micro- and macrovascular complications, and improved international standardization of measurement, our data support use of an HbA1c cut-off point between $6.6 \%$ and $7.0 \%$ in diagnosing diabetes. $[43,45,47,51]$ However, it will be important to examine the impact of using alternative tests of glycaemia or other diagnostic strategies, to identify those with microvascular complications. The public health impact of such strategies should also be carefully examined as the detection of these complications early will have an impact on healthcare resource use and the benefits of such early detection must be clearly delineated.

\section{Limitations of the study}

The study was conducted in a single hospital with small sample size. So, the results may not represent the whole community.

\section{CONCLUSIONS}

The screening for microalbuminuria is not yet consistently done in Bangladesh. Being a developing country; there is a dire need that microalbuminuria and $\mathrm{HbA} 1 \mathrm{c}$ testing should be done in both, newly diagnosed as well as already diagnosed diabetic patients as an early marker of renal risk factor. Strict glycaemic control, having a healthy lifestyle, maintaining standard body weight is especially important for diabetic patients and for those with a family history of diabetes. [] $]$ 
Annals of International Medical and Dental Research

E-ISSN: 2395-2822 | P-ISSN: 2395-2814

Vol-8, Issue-2 | March-April 2022

DOI: 10.53339/aimdr.2022.8.2.14

Page no- 99-108 | Section- Research Article (Medicine)

\section{REFERENCES}

1. WHO Expert Committee on Diabetes Mellitus: second report. World Health Organ Tech Rep Ser. 1980;646:1-80.

2. Al-Maskari F, El-Sadig M, Obineche E. Prevalence and determinants of microalbuminuria among diabetic patients in the United Arab Emirates. BMC Nephrol. 2008;9:1. doi: 10.1186/1471-2369-9-1.

3. King H, Aubert RE, Herman WH. Global burden of diabetes, 1995-2025:prevalence, numerical estimates, and projections. Diabetes care. 1998;21(9):1414-31.

4. Satchell SC, Tooke JE. What is the mechanism of microalbuminuria in diabetes: a role for the glomerular endothelium?. Diabetologia. 2008;51(5):714-25.

5. Sheikh SA, Baig JA, Iqbal T, Kazmi T, Baig M, Husain SS. Prevalence of microalbuminuria with relation to glycemic control in type-2 diabetic patients in Karachi. Journal of Ayub Medical College Abbottabad. 2009 Sep 1;21(3):83-6.

6. Gatling W, Knight C, Hill RD. Screening for early diabetic nephropathy: which sample to detect microalbuminuria?. Diabetic Medicine. 1985 Nov; 2(6):451-5.

7. Mogensen CE. Microalbuminuria and hypertension with focus on type 1 and type 2 diabetes. Journal of internal medicine. 2003 Jul;254(1):45-66.

8. Maahs DM, Snively BM, Bell RA, Dolan L, Hirsch I, Imperatore $G$, et al. Higher prevalence of elevated albumin excretion in youth with type 2 than type 1 diabetes: the SEARCH for Diabetes in Youth study. Diabetes care. 2007;30(10):2593-8.

9. Kassab A, Ajmi T, Issaoui M, Chaeib L, Miled A, Hammami M. Homocysteine enhances LDL fatty acid peroxidation, promoting microalbuminuria in type 2 diabetes. Annals of clinical biochemistry. 2008;45(5):476-80.

10. Marshall SM. Natural history and clinical characteristics of CKD in type 1 and type 2 diabetes mellitus. Advances in chronic kidney disease. 2014 May 1;21(3):267-72.

11. Bruno G, Merletti F, Biggeri A, Bargero G, Ferrero S, Pagano G, et al. Progression to overt nephropathy in type 2 diabetes: the Casale Monferrato Study. Diabetes care. 2003;26(7):2150-5.

12. American Diabetes Association. Nephropathy in diabetes. Diabetes care. 2004;27(suppl 1):s79-83.
13. Golden S, Boulware LE, Berkenblit G, Brancati F, Chander G, Marinopoulos S, et al. Use of glycated hemoglobin and microalbuminuria in the monitoring of diabetes mellitus. Evid Rep Technol Assess (Summ). 2003;(84):1-6.

14. Mogensen CE, Kerne WF, Bennett PH, Jerums G, Parving HH, Passa P, Steffes MW, Striker GE, Viberti GC. Prevention of diabetic renal disease with special reference to microalbuminuria. The Kidney and Hypertension in Diabetes Mellitus. 1998:547-57.

15. Marre M, Chatellier G, Leblanc H, Guyene TT, Menard J, Passa P. Prevention of diabetic nephropathy with enalapril in normotensive diabetics with microalbuminuria. British Medical Journal. 1988 Oct 29;297(6656):1092-5.

16. Mogensen CE, Chachati A, Christensen CK, Close CF, Deckert T, Hommel E, Kastrup J, Lefebvre P, Mathiesen ER, Feldt-Rasmussen B, Schmitz A. Microalbuminuria: an early marker of renal involvement in diabetes. Uremia investigation. 1985 Jan 1;9(2):85-95.

17. Heymsfield SB, Arteaga C, McManus C, Smith J, Moffitt S. Measurement of muscle mass in humans: validity of the 24-hour urinary creatinine method. The American journal of clinical nutrition. $1983 \mathrm{Mar}$ 1;37(3):478-94.

18. Feldt-Rasmussen B, Borch-Johnsen K, Deckert T, Jensen G, Jensen JS. Microalbuminuria: An important diagnostic tool. Journal of Diabetes and its Complications. 1994 Jul 1;8(3):137-45.

19. Donaghue KC, Chiarelli F, Trotta D, Allgrove J, DahlJorgensen K. Microvascular and macrovascular complications associated with diabetes in children and adolescents. Pediatric diabetes. 2009 Sep;10:195203.

20. Buell C, Kermah D, Davidson MB. Utility of A1C for diabetes screening in the 1999-2004 NHANES population. Diabetes care. 2007;30(9):2233-5.

21. Saudek CD, Kalyani RR, Derr RL. Assessment of glycemia in diabetes mellitus: hemoglobin A1c. The J. Assoc. Physicians India. 2005;53:299-305.

22. Kilpatrick ES. Haemoglobin A1c in the diagnosis and monitoring of diabetes mellitus. J Clin Pathol. 2008;61(9):977-82.

23. McCarter RJ, Hempe JM, Chalew SA. Mean blood glucose and biological variation have greater influence on $\mathrm{HbA} 1 \mathrm{c}$ levels than glucose instability: an 
Annals of International Medical and Dental Research E-ISSN: 2395-2822 | P-ISSN: 2395-2814

Vol-8, Issue-2 | March-April 2022

DOI: 10.53339/aimdr.2022.8.2.14

Page no- 99-108 | Section- Research Article (Medicine)

analysis of data from the Diabetes Control and Complications Trial. Diabetes Care. 2006;29(2):352-5.

24. Poornima AM, Shenoy R, Hegde A. Laboratory assessment of the diabetes scenario with respect to hba1c and microalbuminuria. J Clin Diagn Res. 2010; 4(3):2489-94.

25. Alrawahi AH, Rizvi SG, Al-Riyami D, Al-Anqoodi Z. Prevalence and risk factors of diabetic nephropathy in omani type 2 diabetics in Al-dakhiliyah region. Oman Med J. 2012;27(3):212-6. doi: 10.5001/omj.2012.48.

26. Matsuzawa Y, Tokunaga K, Kotani K, Keno Y, Kobayashi T, Tarui S. Simple estimation of ideal body weight from body mass index with the lowest morbidity. Diabetes research and clinical practice. 1990 Jan 1;10:S159-64.

27. Evans G, Greaves I. Microalbuminuria as predictor of outcome. Shows promise but large prospective trials are needed. BMJ. 1999;318(7178):207-208. doi:10.1136/bmj.318.7178.207

28. Parving $\mathrm{HH}$, Hovind P. Microalbuminuria in type 1 and type 2 diabetes mellitus: evidence with angiotensin converting enzyme inhibitors and angiotensin II receptor blockers for treating early and preventing clinical nephropathy. Curr Hypertens Rep. 2002;4(5):387-93. doi: 10.1007/s11906-002-00693.

29. Forman JP, Fisher ND, Schopick EL, Curhan GC. Higher levels of albuminuria within the normal range predict incident hypertension. J Am Soc Nephrol.2008;19(10):1983-1988.doi:10.1681/ASN. 2008010038

30. Justesen TI, Petersen JL, Ekbom P, Damm P, Mathiesen ER. Albumin-to-creatinine ratio in random urine samples might replace 24 -h urine collections in screening for micro- and macroalbuminuria in pregnant woman with type 1 diabetes. Diabetes care. 2006;29(4):924-5.

31. Schwartz MW, Seeley RJ, Zeltser LM, et al. Obesity Pathogenesis: An Endocrine Society Scientific Statement. Endocr Rev. 2017; 38(4): 267-296. doi: 10.1210/er.2017-00111

32. Tagle R, Acevedo M, Vidt DG. Microalbuminuria: is it a valid predictor of cardiovascular risk? Cleve Clin J Med. 2003;70(3):255-61. doi: 10.3949/ccjm.70.3.255.

33. Saudek CD, Kalyani RR, Derr RL. Assessment of glycemia in diabetes mellitus: hemoglobin A1c. J Assoc Physicians India. 2005;53:299-305.
34. Brownlee M, Hirsch IB. Glycemic variability: a hemoglobin A1c-independent risk factor for diabetic complications. JAMA. 2006;295(14):1707-8.

35. Naz S, Sadaruddin A, Khannum A, Osmani R. Frequency of microalbuminuria in diabetic patients of Islamabad and Rawalpindi. Pak J Med Res. 2007;46(3):70-4.

36. Giunti S, Barit D, Cooper ME. Mechanisms of diabetic nephropathy: role of hypertension. Hypertension. 2006;48(4):519-26.

37. Hebert CJ. Preventing kidney failure: primary care physicians must intervene earlier. Cleve Clin J Med. 2003;70(4):337-44. doi: 10.3949/ccjm.70.4.337.

38. Araki S, Haneda M, Koya D, Hidaka H, Sugimoto T, Isono $\mathrm{M}$, et al. Reduction in microalbuminuria as an integrated indicator for renal and cardiovascular risk reduction in patients with type 2 diabetes. Diabetes. 2007;56(6):1727-30. doi: 10.2337/db06-1646.

39. Wright J, Vardhan A. The problem of diabetic nephropathy and practical prevention of its progression. Br J Diabetes Vasc. 2008;8(6):272-7.

40. Derakhshan A, Akhavan M, Karamifar H. Evaluation of microalbuminuria 4 to 6 years following Type 1 Diabetes in Children. Iranian J Paediatr. 2007;17:2526.

41. Nathan DM, Turgeon H, Regan S. Relationship between glycated haemoglobin levels and mean glucose levels over time. Diabetologia. 2007;50(11):2239-44. doi: 10.1007/s00125-007-0803-0.

42. Saudek CD, Derr RL, Kalyani RR. Assessing glycemia in diabetes using self-monitoring blood glucose and hemoglobin A1c. JAMA. 2006;295(14): 1688-97. doi: 10.1001/jama.295.14.1688.

43. Saudek CD, Herman WH, Sacks DB, Bergenstal RM, Edelman D, Davidson MB. A new look at screening and diagnosing diabetes mellitus. J Clin Endocrinol Metab. 2008;93(7):2447-53. doi: 10.1210/jc.2007-2174.

44. Bennett CM, Guo M, Dharmage SC. $\mathrm{HbA}(1 \mathrm{c})$ as a screening tool for detection of Type 2 diabetes: a systematic review. Diabet Med. 2007;24(4):333-43. doi: 10.1111/j.1464-5491.2007.02106.x.

45. Peters AL, Davidson MB, Schriger DL, Hasselblad V. A clinical approach for the diagnosis of diabetes mellitus: an analysis using glycosylated hemoglobin levels. Meta-analysis Research Group on the Diagnosis of Diabetes Using Glycated Hemoglobin Levels. JAMA. 1996;276(15):1246-52. 
Annals of International Medical and Dental Research

E-ISSN: 2395-2822 | P-ISSN: 2395-2814

Vol-8, Issue-2 | March-April 2022

DOI: 10.53339/aimdr.2022.8.2.14

Page no- 99-108 | Section- Research Article (Medicine)

46. Edelman D, Olsen MK, Dudley TK, Harris AC, Oddone EZ. Utility of hemoglobin A1c in predicting diabetes risk. J Gen Intern Med. 2004;19(12):11751180. doi:10.1111/j.1525-1497.2004.40178.x

47. Rohlfing CL, Little RR, Wiedmeyer HM, England JD, Madsen R, Harris MI, et al. Use of GHb (HbA1c) in screening for undiagnosed diabetes in the U.S. population. Diabetes Care. 2000;23(2):187-91. doi: 10.2337/diacare.23.2.187.

48. Diabetes Control and Complications Trial Research Group, Nathan DM, Genuth S, Lachin J, Cleary P, Crofford O, Davis M, et al. The effect of intensive treatment of diabetes on the development and progression of long-term complications in insulindependent diabetes mellitus. N Engl J Med. 1993;329(14):977-86.doi:10.1056/NEJM19930930329

1401.
49. Intensive blood-glucose control with sulphonylureas or insulin compared with conventional treatment and risk of complications in patients with type 2 diabetes (UKPDS 33). UK Prospective Diabetes Study (UKPDS) Group. Lancet. 1998;352(9131):837-53.

50. The relationship of glycemic exposure ( $\mathrm{HbA} 1 \mathrm{c})$ to the risk of development and progression of retinopathy in the diabetes control and complications trial. Diabetes. 1995 Aug;44(8):968-83.

51. Barr RG, Nathan DM, Meigs JB, Singer DE. Tests of glycemia for the diagnosis of type 2 diabetes mellitus. Ann Intern Med. 2002;137(4):263-72. doi: 10.7326/0003-4819-137-4-200208200-00011.

Source of Support: Nil, Conflict of Interest: None declared. 